\section{Aggressive Multilocular Osteoblastoma in the Mandible: A Rare and Difficult Case to Diagnose}

\author{
Maria Luiza Anjos Pontual ${ }^{1}$, Andréa Anjos Pontual ${ }^{1}$, Rafael Grotta Grempel ${ }^{2}$, \\ Leonardo Rocha Mendes Campos ${ }^{3}$, Antonio de Lisboa Lopes Costa ${ }^{4}$, Gustavo \\ Pina Godoy ${ }^{2}$
}

\author{
'Department of Preventive and \\ Clinical Dentistry, Health Science \\ Center, UFPE - Universidade Federal \\ de Pernambuco, Recife, PE, Brazil \\ ${ }^{2}$ Universidade Estadual da Paraíba, \\ Campina Grande, PB, Brazil \\ ${ }^{3}$ Unipê, João Pessoa, PB, Brazil \\ ${ }^{4}$ UFRN - Universidade Federal do \\ Rio Grande do Norte, Brazil
}

\author{
Correspondence: Maria Luiza \\ dos Anjos Pontual, Estrada do \\ Encanamento, 1342, apt. 1301, \\ Casa Amarela, 52070-000 Recife, \\ PE, Brasil. Tel: +55-81-2126-8342. \\ e-mail: mlpontual@gmail.com
}

Osteoblastoma is a benign neoplasia and is uncommon in the jaws. In some cases, this lesion presents extremely aggressive local characteristics and is termed aggressive osteoblastoma. Because the clinical, radiographic and histopathologic characteristics are similar to those of a variety of benign and malignant tumors, it poses a diagnostic dilemma. This report presents a case of an aggressive osteoblastoma in the mandible and discusses the differential diagnosis of this lesion. A 13-year-old white male sought the Stomatology Clinic at the State University of Paraiba, Campina Grande, PB, Brazil, complaining of asymptomatic swelling on the left side of his face. Cone-beam computerized tomography showed a multilocular, hypodense bone lesion, located in the body of the left mandible and lower third of the ascending ramus. The initial diagnostic hypothesis was juvenile ossifying fibroma or osteosarcoma. After histopathologic examination, the final diagnosis was aggressive osteoblastoma. Surgical resection with a safety margin was performed. There was no evidence of recurrence after a follow-up period of 4 years.
Key Words: osteoblastoma, aggressive osteoblastoma, differential diagnosis, mandible.

\section{Introduction}

Osteoblastoma is a solitary, benign bone neoplasm that is rare in the jaws (1). It corresponds to $1 \%$ of all primary bone tumors $(1,2)$ and $3 \%$ of all benign bone neoplasias (3). This lesion is a neoplastic bone growth characterized by the proliferation of numerous plump osteoblasts forming osteoid and trabeculated bone scattered in a stroma of richly vascularized fibrous conjunctive tissue (2). This histopathologic aspect is similar to the one in the niche of an osteoid osteoma, which is then called a giant osteoid osteoma due to its unlimited growth potential, resulting in differentiation by its greater diameter $(>1.5 \mathrm{~cm})(3)$.

Generally, this lesion affects patients in the first three decades of life, with a male/female sex ratio of $2: 1,(3,4)$. It occurs more frequently in the spinal column $(2,3,5-7)$ and long bones (4-8). Other less common sites are the bones of the skull cap, extremities and face (3). The bones of the face are involved in around 10\% (5) to 15\% $(2,8)$ of the cases, and of these, the mandible is most frequently affected $(2,5,8)$.

Alvares Capelozza et al. (4) performed a systematic review of the English literature involving 66 cases and reported another new case of osteoblastoma. In 2006, Jones et al. (2) added other 24 new cases to the literature and pointed out the need for reports of new cases of osteoblastoma in the jaws to be published in order to elucidate this uncommon neoplasia. Lypka et al. (8) reported a case of aggressive osteoblastoma in the mandible and
Wozniak et al. (9) reported a clinical case of malign transformation of an osteoblastoma in the mandible. In the following year, Harrington et al. (5) reported a case of aggressive osteoblastoma in the maxilla, and more recently, reports of a clinical case of osteoblastoma in the maxilla (10) and another in the mandible were published (11). In 2013 , three more cases of osteoblastoma in the jaws were reported, two of which occurred in the jaw $(6,12)$ and one involved the maxilla (7). Therefore, to date, a total of 98 cases of osteoblastoma in the jaws have been reported.

Although osteoblastomas are considered as benign lesions, in some cases, aggressive behavior may occur in the affected region with atypical histopathologic characteristics (8). Aggressive osteoblastoma is an uncommon presentation and has a greater tendency to recur. Moreover, this lesion presents imaging and histopathologic characteristics similar to those of other lesions, which has led to much discussion about its differential diagnosis.

The aim of this article was to relate a clinical case of aggressive osteoblastoma in the region of the mandible and discuss its differential diagnosis and the up-to-date findings in the literature.

\section{Case Report}

The patient, a 13-year-old white male, sought the Stomatology Clinic at the State University of Paraiba, Campina Grande, PB, Brazil, complaining of asymptomatic swelling on the left side of his face. The patient's mother 
said that the region in his face has been swelling for 10 months. In the extraoral physical examination, consistent swelling was found on palpation on the left side of the mandible (Fig. 1). In the intraoral physical examination, a swollen region was observed in the lingual and vestibular regions and retromolar to the left side of the mandible (Fig. 2). Additionally, were found residual roots of the mandibular left first molar and displacement of both mandibular left premolars and the mandibular left second
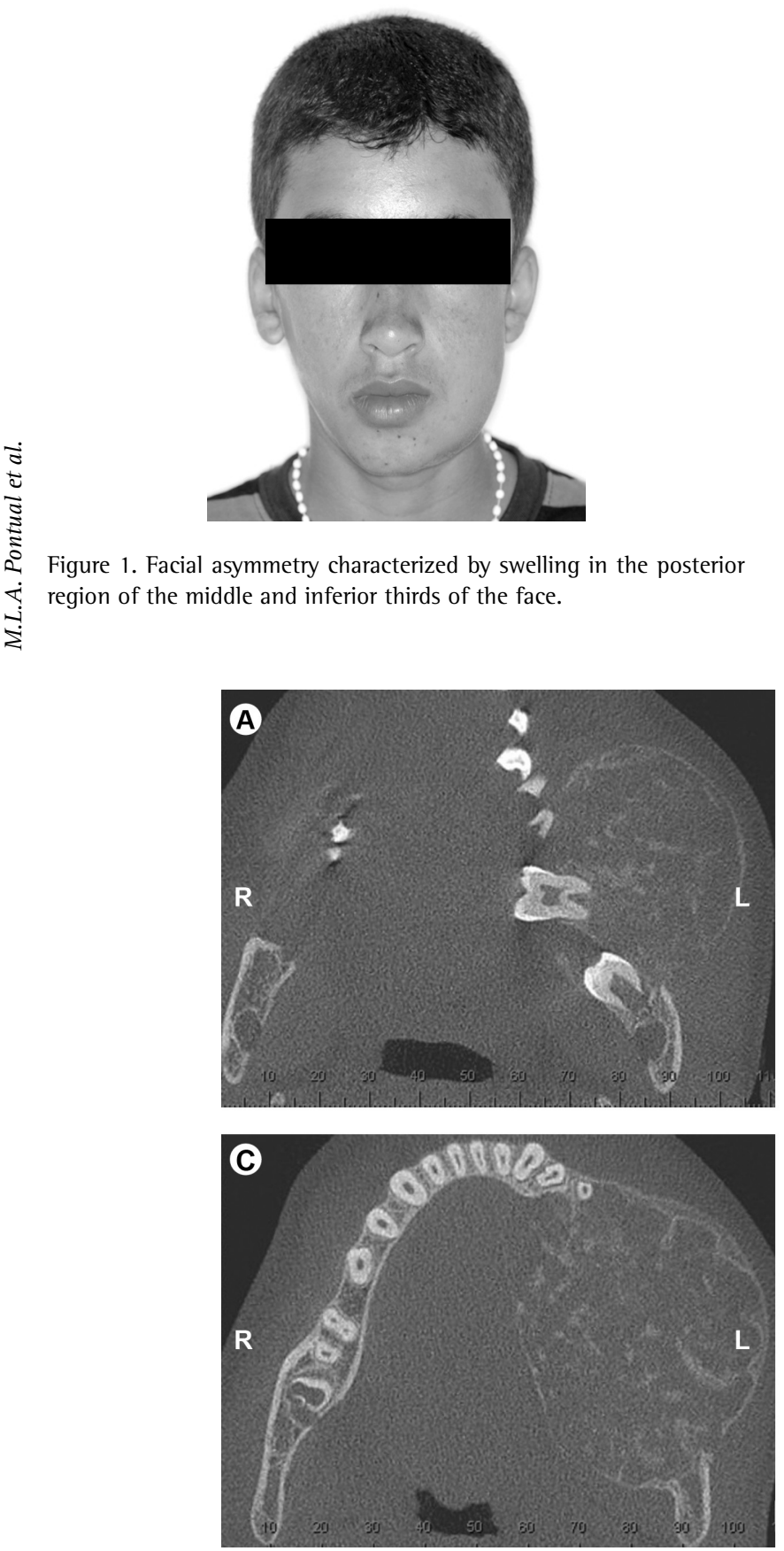

molar.buccalCone-beam computerized tomography showed a multilocular, hypodense bone lesion, with largest diameter of $5.7 \times 4.7 \mathrm{~cm}$, located in the body of the left mandible, extending from the apical region of the mandibular left lateral incisor to the mandibular foramen (Figs. 3-5). Displacement of the mandibular left second premolar, the mandibular left first and second molars and of the germ the mandibular left third molar (Fig. 3) was observed, in addition to inferior displacement of the mandibular canal. The cortical area showed expansion, thinning, and destruction in some regions (Figs. 3 and 4). The initial

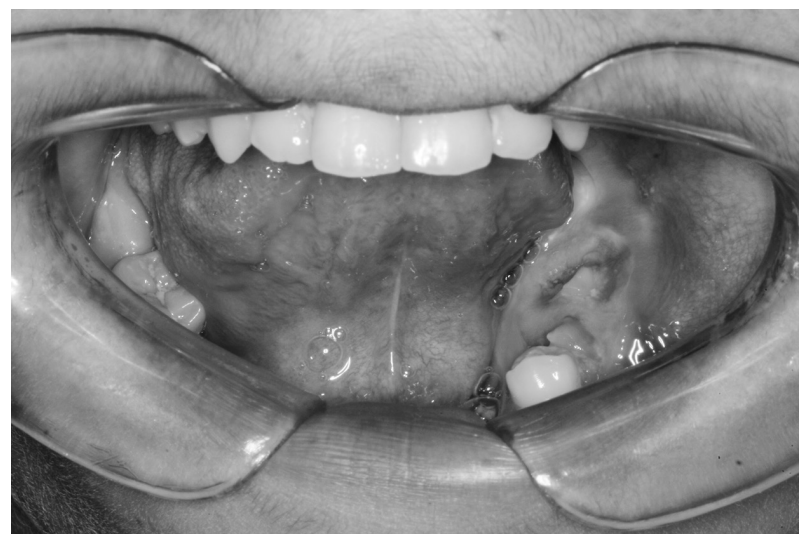

Figure 2. On intraoral examination, tumefaction of the body and retromolar regions were found on the left side of the mandible.

Figure 3. Axial reconstructions (A, B, C) and three-dimensional reconstruction (D) exhibiting horizontal inclusion of the mandibular left second molar, extension of the lesion and effects on the buccal cortical and lingual cortical and teeth. 
diagnostic hypothesis was juvenile ossifying fibroma or osteosarcoma.

With the aid of imaging examinations, an incisional biopsy was performed, which was then sent for histopathologic examination. A stroma of dense conjunctive tissue with randomly disposed collagen fibres was verified with intense vascularization and numerous multinucleated giant cells. The trabeculated bone varied from immature (osteoid) to mature bone tissue. The bony trabeculae exhibited osteoblastic pavimentation, with plump osteoblasts and abundant hyperchromatic cytoplasm disposed in layers. Rare figures of mitosis were observed. Numerous vascular spaces were observed, with an absence of endothelial cell linings. Intense hemorrhagic extravasation completed the microscopic examination of the histology (Fig. 5). The final diagnosis was aggressive osteoblastoma.

Surgical resection and reconstruction with placement of a titanium plate were performed (Fig. 6). There has been no recurrence over a follow-up period of 4 years (Fig. 7).

\section{Discussion}

From our research on the English literature, the present clinical case corresponds to the 99th report of osteoblastoma in the jaws. However, in a PubMed search using the keywords "aggressive osteoblastoma" and "jaws", only six articles were listed, of which only four actually dealt with cases of aggressive osteoblastoma in the jaws. In the case review studies $(1,2,4)$, there was no classification of the osteoblastomas with regard to the aggressive form. Aggressive osteoblastoma is a lesion on the threshold between a conventional osteoblastoma and osteosarcoma,
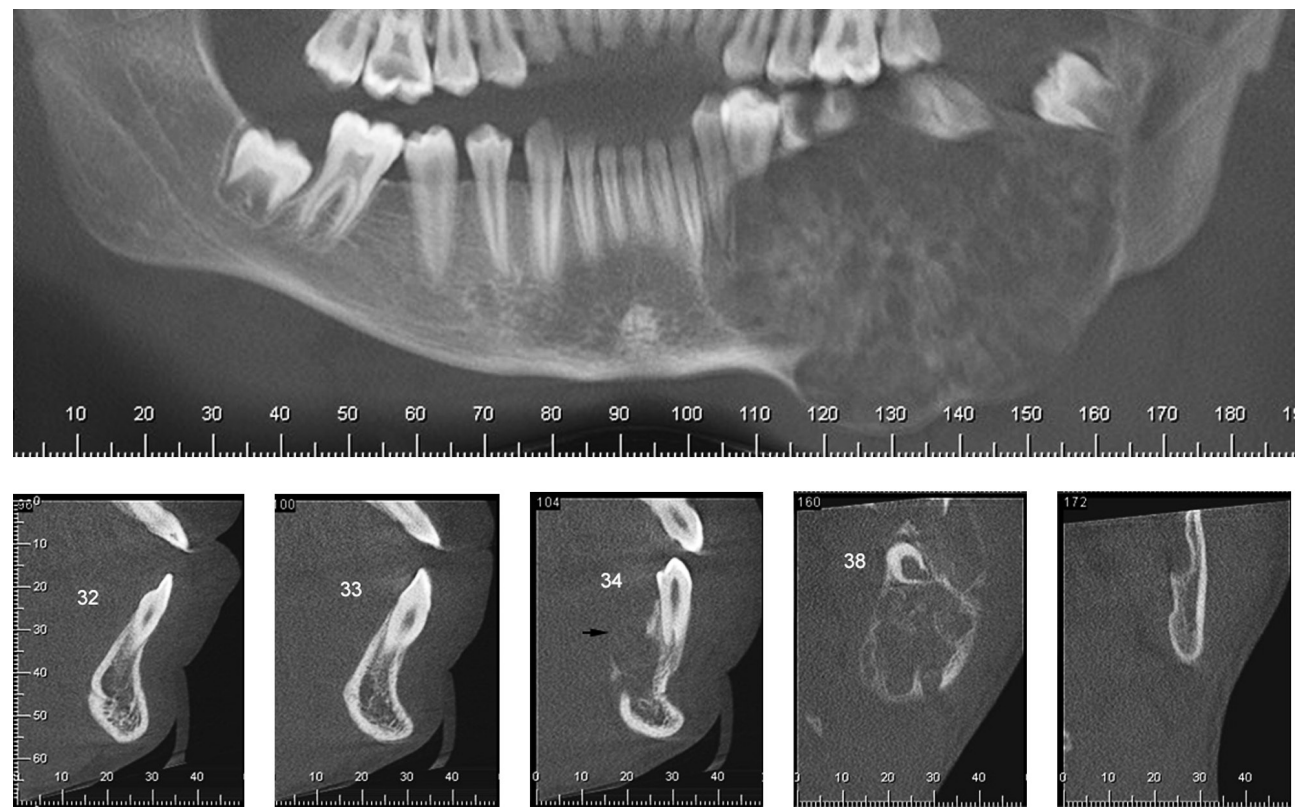

Figure 4. Panoramic coronal reconstruction and parasagittal reconstruction. A multilocular hypodense image is verified, causing expansion, thinning and destruction of the corticals in the mandibular body region on the left side and extending anteriorly up to the region of the mandibular left lateral incisor.
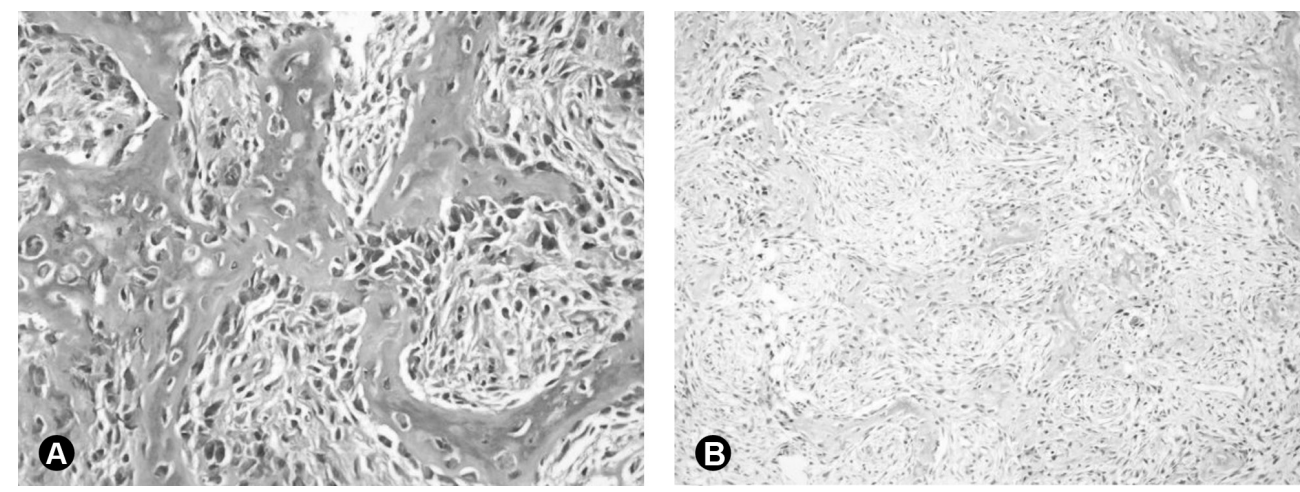

Figure 5. A: Proliferation of fusiform cells interlaced with immature bony trabeculae (hematoxylin and eosin, 100x). B: Bony trabeculae with osteoblastic pavimentation of cells with abundant cytoplasm (hematoxylin and eosin, 400x). 
with a greater tendency to recur despite not metastasizing, and it is characterized microscopically by the presence of plump osteoblasts $(5,11,13)$.

The patient's age in the present case is within the age range of greatest occurrence of conventional osteoblastomas; most cases affect patients aged from 5 to 24 years (2). Furthermore, the patient was in the second decade of life, which is the most prevalent age range $(2,4,9)$. On the other hand, aggressive osteoblastoma is more prevalent in older patients (11). In addition, the patient in the present case is male, the sex most affected in other reports (around 59\% (1) and 70.7\% (14) of cases). However, in the sample of 24 cases of osteoblastoma studied by Jones et al. (2), osteoblastomas were more common in female patients (83.3\% of cases).

Clinically, osteoblastoma may cause edema, bone expansion, and continuous and punctual pain, which may gradually increase $(2,3)$. Except for the pain, the lesion in the present case had these characteristics, similar to the previously reported cases $(1,2,4,15,16)$. Although pain is considered a frequent characteristic of this lesion $(1,4,14)$, the absence of pain symptomatology at the time of diagnosis may occur in $7.2 \%$ of cases of osteoblastoma (4). Other studies have verified a higher frequency of the absence of symptomatology in 25\% (1) and 50\% (2) of cases. In the present case, the patient did not complain until the lesion was diagnosed, similar to what was found in the previously reported cases $(4,15)$. Thus, many cases of osteoblastomas are discovered by routine radiographic examination, or as a result of investigating the facial swelling caused by the lesion, as seen in the reports by Utumi et al. (17) and in the present case.

Evaluating the cases published in the literature, the mandible was the most involved region of the maxillofacial complex $(1,2,4,6,7)$. The lesion in the present case occurred in the posterior region on the left side of the mandible, the
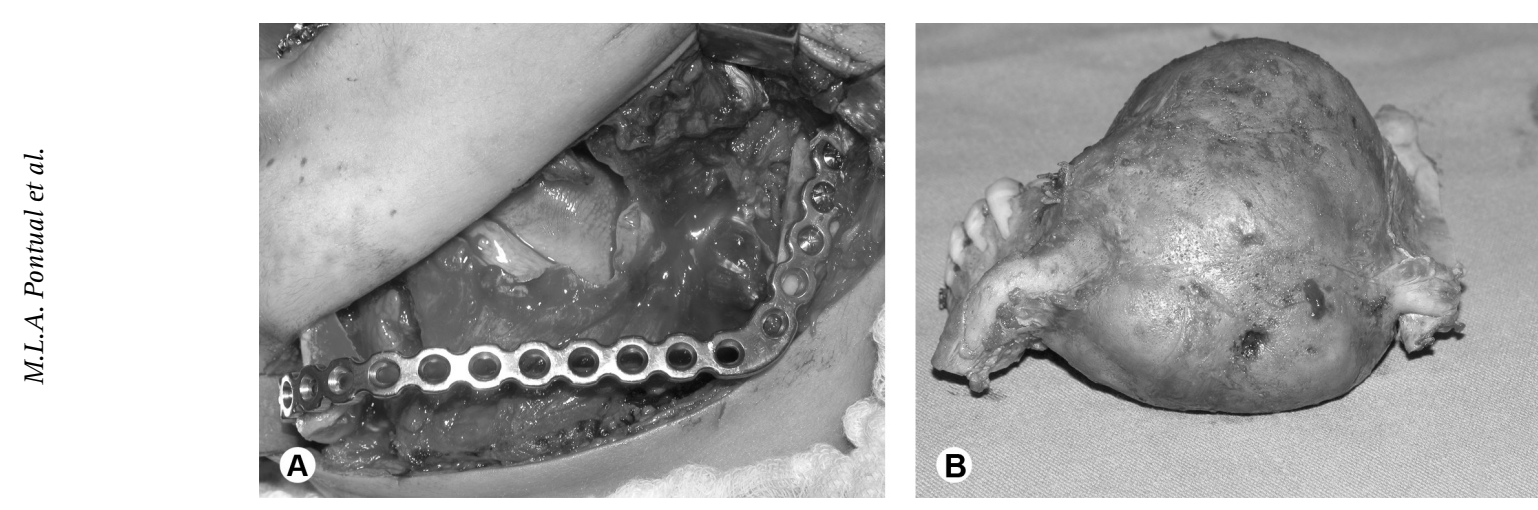

Figure 6. A: Resection of the mandible was performed with a safety margin and a titanium plate inserted. B: Gross specimen.
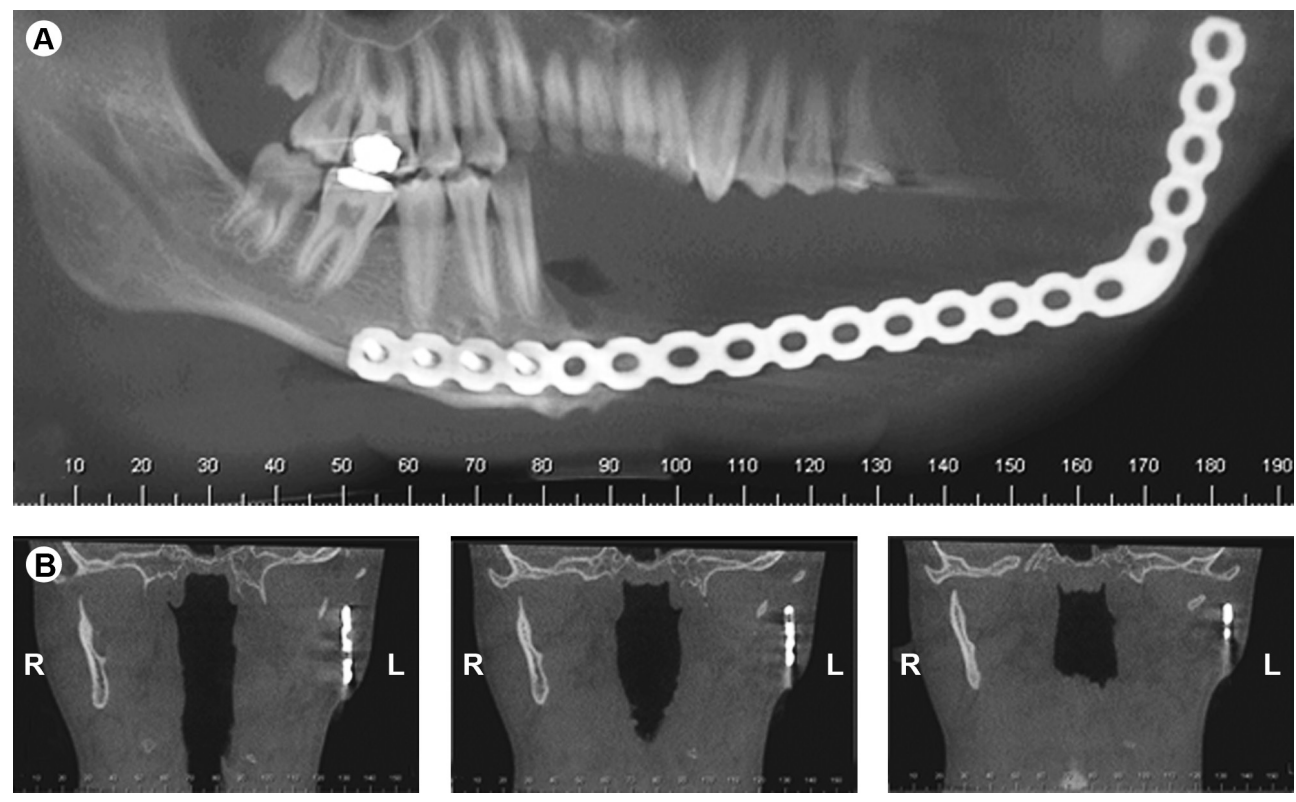

Figure 7. A: Panoramic coronal reconstruction 3 years after treatment. B: Coronal reconstruction 3 years after treatment. 
most commonly affected site and side (81.8\% and 63.7\% of cases, respectively) (2).

The radiologic view of a multilocular lesion in the present case is uncommon; this occurred in only 2 of 77 cases reviewed by Jones et al. (2). The imaging features of osteoblastoma are variable, with a variety of patterns (4). These lesions may present as lytic or mixed images or even as sclerotic masses. Some lesions present a radiopaque nidus within a radiolucent area, similar to an osteoid osteoma, which also presents histopathologic characteristics similar to those of osteoblastoma, differentiated by the size of the lesion (18). Osteoid osteomas are limited to lesions between 1 and $2 \mathrm{~cm}$ diameter, whereas osteoblastomas are larger, as in the present case. A similar situation occurs for the density involving the roots of teeth, which may resemble an cementoblastoma (19). Some lesions may exhibit considerable calcification (4), making them resemble unpolished glass, similar to fibrous dysplasia.

The margins of an osteoblastoma may range from well to poorly defined $(1,2,4)$. In the present case, most of the margins were defined, with an ill-defined area in the anterior region, so it was difficult to determine the anterior extent of the lesion. This characteristic may suggest the potential aggressive nature of the lesion, leading to expansion, perforation, or cortical destruction (2).

In the present case, the diameter of the lesion was $>4$ $\mathrm{cm}$, which is an indication of aggressive osteoblastoma. Conventional osteoblastomas have limited growth potential and typically do not exceed $4 \mathrm{~cm}$ diameters (11).

The imaging features of osteoblastoma are not conclusive and may mimic other conditions, ranging from cementoblastoma, osteoid osteoma, fibrous dysplasia, ossifying fibroma, focal cemento-osseous dysplasia, to borderline forms of the above malignancies, to low-grade osteosarcoma $(11,19)$. In the present case, the images resembled juvenile ossifying fibroma and low-grade osteosarcoma such as in the cases reported by Badauy et al. (15) and Strobel et al. (12), respectively. Juvenile ossifying fibroma has clinical and imaging features similar to those of osteoblastoma and is usually observed in young patients; it occurs more frequently in the posterior region of the mandible (15) and can be differentiated after histopathologic examination.

Approximately a quarter of osteoblastomas show imaging features of malignancy $(11,12)$ resembling low-grade osteosarcoma. Osteosarcoma is the most important condition that must be considered in the differential diagnosis, and it is difficult to distinguish this lesion from aggressive osteoblastoma $(16,19-21)$. However, osteosarcoma does not present well-defined margins. Microscopically, it contains atypical osteoblasts and malignant bone formation, capable of presenting sarcomatous stroma, as well as anaplastic cartilage $(5,10,14,16)$.

In the present case, it was only after the histopathologic examination that the lesion was diagnosed as aggressive osteoblastoma. Aggressive osteoblastoma is a threshold osteoblastic neoplastic lesion, with the presence of large epitheloid osteoblasts suggesting a distinct histologic characteristic $(5,8,16)$. Moreover, increase in mitotic activity and non-trabecular sheets or lace-like areas of osteoid production are also characteristics associated with osteoblastoma. In the present case, these characteristics, with the exception of the increase in mitotic activity, were verified, as in previous reports $(5,11,16)$.

Nevertheless, other authors do not consider that the histologic characteristics alone are a reliable predictor of aggressive behavior; there are more important clinical and imaging features (5). Aggressive osteoblastomas grow rapidly and tend to invade adjacent tissues (9), as was verified in the present case.

The probability of recurrence is $13.6 \%$ for conventional osteoblastoma and 50\% for aggressive osteoblastoma (1). Therefore, differentiation between conventional and aggressive osteoblastoma is important to establish treatment to avoid recurrences. Surgical resection with a safety margin and later reconstruction are the recommended treatments $(5,11,16,22)$. Thus, in the present case, resection with a safety margin and primary reconstruction with a titanium plate were performed. No signs of recurrence have been verified in the 4 years since surgery. In previous cases treated with surgical resection of aggressive osteoblastoma in the jaws, no recurrence was verified up to 8 months (5), 1 year (14), and 2 years $(19,22)$ after treatment.

In conclusion, osteoblastoma is a disease that presents clinical, imaging, and histopathologic characteristics similar to those of other lesions and is difficult to diagnose. In addition, it may present an aggressive form, which must be correctly diagnosed for effective treatment in order to avoid possible recurrences. The present case is an important example of the association of clinical, imaging and histopathologic findings for the diagnosis of this lesion. Moreover, more case reports and studies on the aggressive form of osteoblastoma involving the jaws are required to enable a better understanding of the behavior of this lesion.

\section{Resumo}

0 osteoblastoma é uma neoplasia benigna e incomum nos maxilares. Em alguns casos esta lesão apresenta caracteristicas locais extremamente agressivas, sendo denominada osteoblastoma agressivo. Devido às características clínicas, radiográficas e histopatológicas serem similares a uma variedade de tumores benignos e malignos, o seu diagnóstico é um dilema. Este relato apresenta o caso de um osteoblastoma agressivo na mandibula e discute o diagnóstico diferencial desta lesão. Paciente, branco, 13 anos de idade, foi atendido na Clínica de Estomatologia da Universidade Estadual da Paraiba, Campina Grande, PB, Brasil, queixando-se de aumento 
de volume assintomático do lado esquerdo de sua face. A tomografia computadorizada de feixe cônico revelou uma lesão óssea hipodensa multilocular, localizada no corpo do lado esquerdo da mandibula e no terço inferior do ramo ascendente da mandíbula. A hipótese diagnóstica foi de fibroma ossificante juvenil e osteosarcoma. Após exame histopatológico, o diagnóstico final foi osteoblastoma agressivo. Foi realizada ressecção cirúrgica com margem de segurança. Não houve sinais de recorrência após 4 anos de acompanhamento.

\section{References}

1. Gordon SC, MacIntosh RB, Wesley RK. A review of osteoblastoma and case report of metachronous osteoblastoma and unicystic ameloblastoma. Oral Surg Oral Med Oral Pathol Oral Radiol Endod 2001;91:570-575.

2. Jones AC, Prihoda TJ, Kacher JE, Odingo NA, Freedman PD. Osteoblastoma of the maxilla and mandible: a report of 24 cases, review of the literature, and discussion of its relationship to osteoid osteoma of the jaws. Oral Surg Oral Med Oral Pathol Oral Radiol Endod 2006; 102: 639-650.

3. Sabedotti IF, Toigo FT, Ferrarini I, Montemór-Netto MR. Vertebral column aggressive osteoblastoma: two cases report and literature review. Rev Imagem 2007;29:29-34.

4. Alvares Capelozza AL, Gião Dezotti MS, Casati Alvares L, Negrão Fleury $R$, Sant'Ana E. Osteoblastoma of the mandible: systematic review of the literature and report of a case. Dentomaxillofac Radiol 2005;34:1-8.

5. Harrington $\mathrm{C}$, Accurso BT, Kalmar JR, Iwenofu OH, Agrawal A, Allen $\mathrm{CM}$, et al.. Aggressive osteoblastoma of the maxilla: a case report and review of the literature. Head Neck Pathol 2011;5:165-170.

6. Mahajan A, Kumar P, Desai K, Kaul RP. Osteoblastoma in the retromolar region - Report of an unusual case and review of literature. J Maxillofac Oral Surg 2013;12:338-340.

7. Shah S, Kim JE, Huh KH, Yi WJ, Heo MS, Lee SS. Recurrent osteoblastoma of the maxilla. Dentomaxillofac Radiol 2013;42:1-5.

8. Lypka MA, Melrose R, Rizvi M, Urata M, Hammoudeh J. A mandibular mass in a pediatric patient. J Oral Maxillofac Surg 2011;69:1661-1667.

9. Woźniak AW, Nowaczyk MT, Osmola K, Golusinski W. Malignant transformation of an osteoblastoma of the mandible: case report and review of the literature. Eur Arch Otorhinolaryngol 2010;267:845-849.

10. Bokhari K, Hameed MS, Ajmal M, Togoo RA. Benign osteoblastoma involving maxilla: a case report and review of the literature. Case Rep Dent 2012;2012:1-4.

11. Kaur H, Verma S, Jawanda MK, Sharma A. Aggressive osteoblastoma of the mandible: a diagnostic dilemma. Dent Res J 2012;9:334-337.

12. Strobel $K$, Merwald $M$, Huellner $M$, Zenklusen HR, Kuttenberger J. Osteoblastoma of the mandible mimicking osteosarcoma in FDG PET/ CT imaging. Clin Nucl Med 2013;38:143-144.

13. Dorfman HD, Weiss SW. Borderline osteoblastic tumors: problems in the differential diagnosis of aggressive osteoblastoma and low-grade osteosarcoma. Semin Diagn Pathol 1984;1:215-234.

14. McLeod RA, Dahlin DC, Beabout JW. The spectrum of osteoblastoma. AJR Am J Roentgenol 1976;126:321-325.

15. Badauy C, Carrard V, Rados P, Sant'ana Filho M. Radiopaque mass of the posterior mandible with lingual expansion. J Oral Maxillofac Surg 2007;65:2498-2502.

16. Lypka MA, Goos RR, Yamashita DD, Melrose R. Aggressive osteoblastoma of the mandible. Int J Oral Maxillofac Surg 2008;37:675-678.

17. Utumi ER, Sales MAO, Yamamoto FP, Cavalcanti GP. Difficulty in diagnosing atypical osteoblastoma of the face: case report. Int Arch Otorhinolaryngol 2010;14:127-130.

18. Rahsepar B, Nikgoo A, Fatemitabar SA. Osteoid osteoma of subcondylar region: case report and review of the literature. J Oral Maxillofac Surg 2009;67:888-893.

19. Rawal YB, Angiero F, Allen CM, Kalmar JR, Sedghizadeh PP, Steinhilber AM. Gnathic osteoblastoma: clinicopathologic review of seven cases with long-term follow-up. Oral Oncol 2006;42:123-130.

20. Lee HM, Cho KS, Choi KU, Roh HJ. Aggressive aneurysmal bone cyst of the maxilla confused with telangiectatic osteosarcoma. Auris Nasus Larynx 2012;39:337-340.

21. Mahajan S, Srikant N, Boaz K, George T. Osteoblastoma of maxilla with cartilaginous matrix: review of literature and report of a case. Singapore Dent J 2007;29:12-18.

22. Vigneswaran $N$, Fernandes $R$, Rodu $B$, Baughman RA, Siegal GP. Aggressive osteoblastoma of the mandible closely simulating calcifying epithelial odontogenic tumor. Report of two cases with unusual histopathologic findings. Pathol Res Pract 2001;197:569-576.

Received September 9, 2014 Accepted September 11, 2014 